タノールの特異性については, さらに重合度を変化させて検討することにしたい。

付 印：本報告を発表することを許可された会社当局ならびに有益なご助言をいただいた東工大河合徽氏に感謝 する。な抗この報告は高分子学会第 6 回年次大会 (1957.6.1 東京) に㧍いて発表した。

文献

1) 内藤, 浮田, 小南：高化, 14, 117(1957)

2) R.P. Airapetova and N.T. Redkorebrova: Zhur. Obshchei Khim., 26, 668(1956) ; Chem. Abstr., 50, 16319 i (1956)

\title{
Studies on the Solution of Polyvinyl Acetate
}

\section{Effect of Concentration and Solvent on the Apparent Activation Energy of Flow of Polyvinyl Acetate Solution}

By Ryunosuke Naito

The apparent activation energy $E_{r_{1}}$ of flow was obtained for both the solution of polyvinylacetate and the mixture of the ordinary solvents. (1) The relation of $E_{\eta}$ of the low molecular solution with composition is correlated with the degree of interaction between the two components. (2) $E_{r}$ of polyvinyl acetate solution increases linearly with concentration when aceton, benzene and other good solvents are used as solvent. In the case of methanol, poor solvent, this relation has minimum. (3) When the mixed solvent, aceton-water, is used, this relation has minimum, too, for the solution above 20 vol $\%$ of water. (4) Such behavior of activation energy as mentioned above, are explainable qualitatively by the energy formula for the two components solution.

第 2 報 ポリ酢酸ビニル溶液の流動の活性化エネルギーに

及ぼす重合度ならびに分岐の影響

(1957 年 8 月 8 日受理)

内滕 龍之介

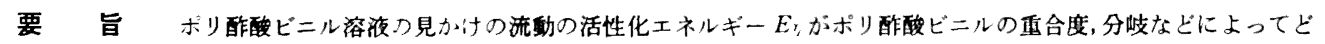
のように変化するかについて梭討し, 次のような結果を得た。(1) アセトン,ペンゼンのような良溶媒の溶液においては $E_{\eta_{i}}$ は

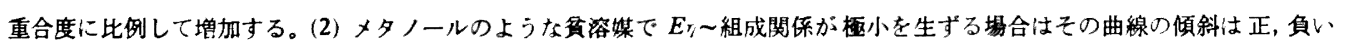
ずれの場合も重合度の大きい方が大き。(3) 極小をとる䈨度は重合度に無関倸で一定であり2只付近である。(4)以上の実 験事実はニネルギー式を用いて定性的に説明することができる。

緒言

前報”において流動の活性化ェネルギーと溶液濃度との関倸について検討したが、ここではポリ酢酸ビニ ル(以下 PVAc と略記)の重合度, 分岐度がこれらにどのような影響を与えるかについて調べてみた。

試料ならびに实験方法

実験に用いたPVAc はすべて分別物であり，その性質を第 1 表に示す。

実験方法は前報”と同しである。 
第 1 品 試料 PVAc の性質

\begin{tabular}{|c|c|c|c|c|c|}
\hline 番号 & 重合温度 & 重合率 & 重合溶媒 & 重合度 & 分裂数* $K \times 10^{4}$ \\
\hline $\begin{array}{l}A-1 \\
A-2 \\
A-3 \\
A-4\end{array}$ & $50^{\circ} \mathrm{C}$ & $60 \%$ & $\begin{array}{c}\text { メタール } \\
10 \%\end{array}$ & $\begin{array}{r}4720 \\
4620 \\
1570 \\
956\end{array}$ & \\
\hline $\begin{array}{l}\text { B-1 } \\
\text { B-2 }\end{array}$ & $50^{\circ} \mathrm{C}$ & $10^{\circ}$ & 塊状 & $\begin{array}{l}1120 \\
1914\end{array}$ & $\begin{array}{l}-1.15 \\
-0.287\end{array}$ \\
\hline $\begin{array}{l}\text { B - } 3 \\
\text { B - } 4 \\
\text { B-5 }\end{array}$ & $50^{\circ} \mathrm{C}$ & $90 \%$ & 塊状 & $\begin{array}{l}3929 \\
4038 \\
5795\end{array}$ & $\begin{array}{l}2.12 \\
2.46 \\
2.70\end{array}$ \\
\hline $\begin{array}{l}\text { C }-1 \\
\text { C }-2 \\
\text { C }-3 \\
\text { C }-4 \\
\text { C }-5 \\
\text { C }-6\end{array}$ & $50^{\circ} \mathrm{C}$ & $60 "$ & $\begin{array}{c}\text { メタノール } \\
20 \%\end{array}$ & $\begin{array}{r}3873 \\
3484 \\
2742 \\
1982 \\
1469 \\
973\end{array}$ & $\begin{array}{c}0.887 \\
0.603 \\
0.532 \\
0.502 \\
0.484 \\
-\end{array}$ \\
\hline $\begin{array}{l}D-1 \\
D-2 \\
D-3 \\
D-4\end{array}$ & $60^{\circ} \mathrm{C}$ & $60 \%$ & 塊状 & $\begin{array}{l}3720 \\
3389 \\
3007 \\
1520\end{array}$ & $\begin{array}{c}1.758 \\
1.303 \\
1.203 \\
-\end{array}$ \\
\hline
\end{tabular}

* 試料をケン化して PVA とし $K=\left(P_{A} P_{A}-1\right) / P_{A C}$ として求めた。

\section{宾倹 結 果}

1. 重合度の影整 A-1〜A-4の4つの分別試料についてアセトンおよびメタノール溶液の活性化エ

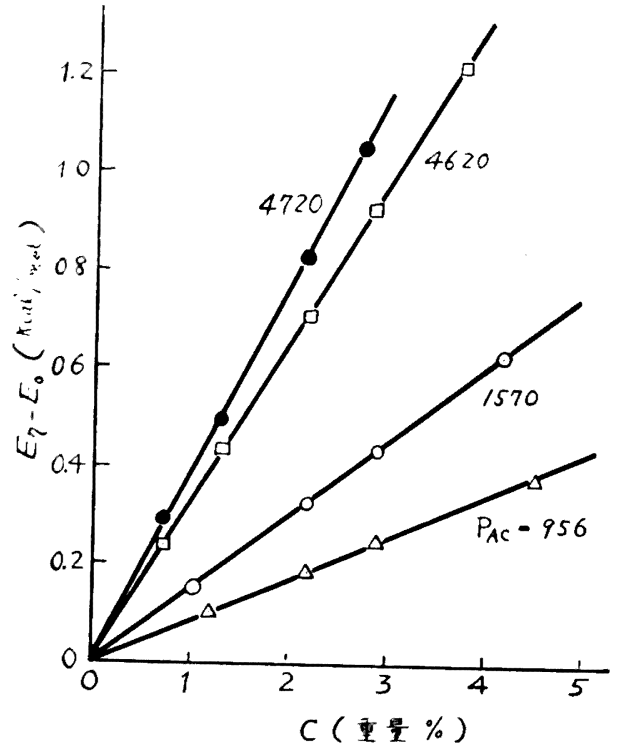

第1 1 図PVAc-アセトン系の流動の 活性化エネルギー
ルギーとPVAc 濃度との関係を第 1 図および第 2 に示す。第1図より明らかなようにアセトン溶液

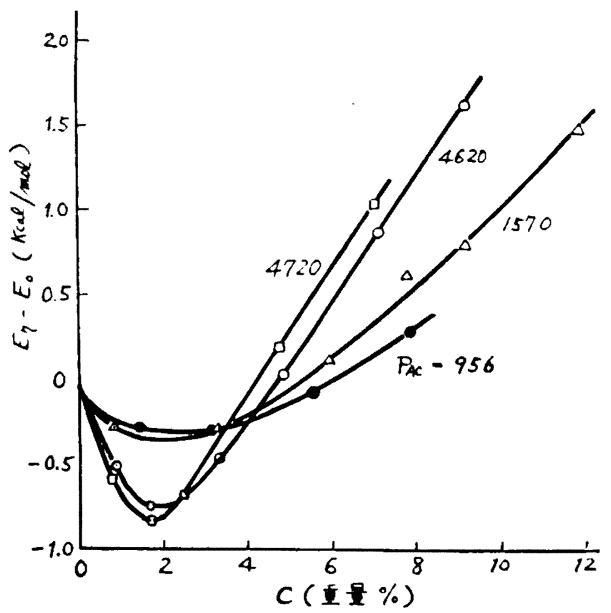

部 2 図PVAcメタノール溶液の流 動の活性化エネルギー 
おける $E_{r}-E_{0}$ の值 $\left(E_{0}\right.$ は純溶媒の $\left.E_{\eta}\right)$ は PVAc 濃度とともにほぼ直線的に比例し, さらにその傾斜は重合度 に比例して増加している。この結果は PVA 水溶液 ${ }^{2}$ の場合と全く同様である。第 2 図にみられるメタノー ルの場合は前報1で示したようにいずれも極小を持つ 曲線となるが，その傾斜は正負いずれの場合も重合度 の大きい方が大き:。しかも興味あることはこの極小 をとる濃度は重合度に無関倸で一定(約 $2 \circ$ ○)である。

2. 分汥度の異なるPVAcについての比較重合 条件を相違してつくったPVAc を分別して，分岐度 の異なると考えられる試料をつくって比較した。分岐 の尺度としては PVA の重合度に対する比を示す分裂 数 $K$ を用い, $K$ の值は $0 \sim 3 \times 10^{-4}$ の範囲である。同 一重合物でも重合度の大きい方が $K$ の值は大きいよ らである。

100 溶液(ア七トン)の $E_{\tau}$ を測定しこれと重合度と をプロットすると第 3 図のようになり，測定螌囲では 分岐度によって $E_{r}$ の值はあまり変化していないよう である。

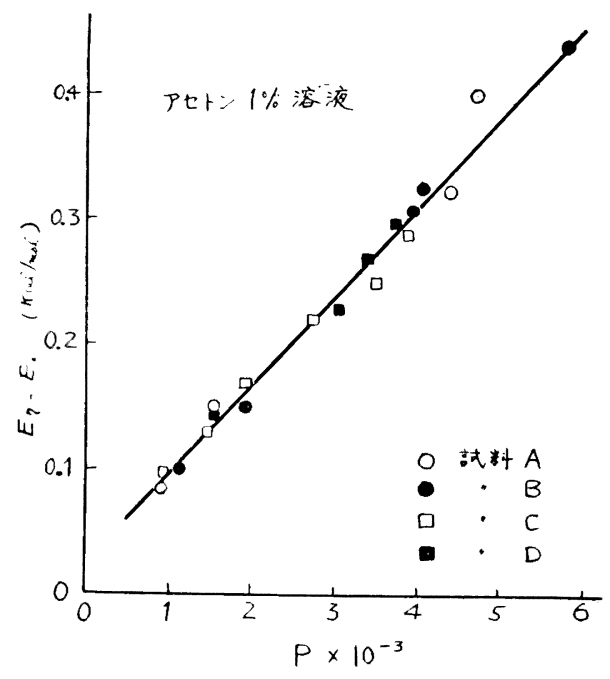

第 3 図 分岐度のことなる種々の PVAc 分別物 のア七トン溶液の流動の活性化エネルギー

\section{若}

察

流動の活性化エネルギーが重合度によって直線的に変化することは PVA 水溶液2゙あいは PVAcの厂七 トン,ベンゼン溶液などの場合について確かめられた。もし流動単位がセグンメトであると考えれば，重合 度の効果は主としてポリマー連鎖の末端七グメントの効果に㷌せしめることができる。いま末端のセグメン トを第 3 成分と考え， 3 成分混合采のエネルギーの式を書くと次のよ5に表わすことができる。

$$
\begin{aligned}
E=\nu_{11} x_{1}{ }^{2} & +\nu_{22}\left(\frac{p-2}{p}\right)^{2} x_{2}{ }^{2}+\nu_{2 / 2}\left(\frac{2}{p}\right)^{2} x_{2}{ }^{2} \\
& +2 \nu_{12} x_{1} x_{2}\left(\frac{p-2}{p}\right)+2 \nu_{12}, \frac{2}{p} x_{1} x_{2}+2 \nu_{22}, x_{2}{ }^{2}\left(\frac{2}{p}\right)\left(\frac{p-2}{p}\right)
\end{aligned}
$$

ただし複雑さを避けるため，上式はセグメントの大きさと溶媒分子の大きさとを等しいと仮定した式である。 ここにpは1分子中の流動単位の数, $2^{\prime}$ は末端のセグメントを表わし, $x_{1}$ は溶媒のモル分率, $x_{2}$ は全体の七 グメントのモル分率である。これを整理すると

$$
\begin{gathered}
E=\nu_{11} x_{1}{ }^{2}+A x_{2}{ }^{2}+B x_{1} x_{2} \\
A=\nu_{22}\left(\frac{p-2}{p}\right)^{2}+2 \nu_{22},\left(\frac{2}{p}\right)\left(\frac{p-2}{p}\right)+\nu_{2 / 2}\left(\frac{2}{p}\right)^{2} \\
\fallingdotseq \nu_{22}+4\left(\nu_{22},-\nu_{22}\right) / p \\
B=2 \nu_{12}\left(\frac{p-2}{p}\right)+4 \nu_{12} / p=2 \nu_{12}+4\left(\nu_{12},-\nu_{12}\right) / p
\end{gathered}
$$




$$
\begin{aligned}
\therefore \quad d E / d x_{2}=2[ & \left\{2\left(\nu_{12},-\nu_{12}\right) / p+\nu_{12}-\nu_{11}\right\}+\left\{\nu_{11}+\nu_{22}\right. \\
& \left.\left.+4\left(\nu_{22},-\nu_{22}\right) / p-2 \nu_{12}-4\left(\nu_{12},-\nu_{12}\right) / p\right\} x_{2}\right]
\end{aligned}
$$

普通末端は，より流動しやすいから $\nu_{12},<\nu_{12}$ である。

(3)式より

$$
\left(d E / d x_{2}\right)_{x_{2}=0}=2\left[2\left(\nu_{12},-\nu_{12}\right) / p+\nu_{12}-\nu_{11}\right]
$$

分子量が大きいほどpの值は大きく，したがって［］の中の第１項は小さくなり，傾斜は大きくなる。 の結果はア七トン溶液の場合にはうまく説明できるが，メタノール溶液のように極小を生ずる場合を説明 ることができない。

これに対して少し乱暴であるが，流動単位を分子自身と考え，第 1 報のエネルギー式(1)がそのまま高分 の場合にも拡張できると仮定すると（すなわち $V_{2}$ を高分子 1 個の占める流動学的な体積と考える）

$d E / d x_{2}=\left[1 / V_{1}\left(a x_{2}+1\right)^{2}\right]\left[a\left(f_{11}+f_{22}-2 f_{12}\right) x_{2}{ }^{2}+2\left(f_{11}+f_{22}-2 f_{12}\right) x_{2}+2 f_{12}-(a+2) f_{11}\right]$ 〔第 1 報(2) 式〕 より

$$
\begin{aligned}
\left(d E / d x_{2}\right)_{x_{2}=} & =\left(1 / V_{1}\right)\left[2 f_{12}-(a+2) f_{11}\right] \\
& =\left(1 / V_{1}\right)\left[2 C_{12} V_{1} V_{2}-\left(V_{2} / V_{1}+1\right) C_{11} V_{1}{ }^{2}\right] \\
& =2 C_{12} V_{2}-C_{11} V_{2}-C_{11} V_{1}=V_{2}\left(2 C_{12}-C_{11}\right)-C_{11} V_{1}
\end{aligned}
$$

となるから $\left(d E / d x_{2}\right)_{x_{2}=0}$ が正であっても負であっても， その絶対值は $V_{2}$ の大きいほど大きく重合度による効果を いずれの場合もうまく説明することができる。ここに $f_{11}$, $f_{12}, f_{22}$ は第 1 報”に述べたようにそれぞれの系の混合ェネ ルギーに関するパラメーターであり系の凝集ェネルギー密 度 $C_{11}, C_{12}, C_{22}$ および溶媒, 溶犋のモル容稙 $V_{1}, V_{2}$ との 間に次のような関係がある。

$$
f_{11}=C_{11} V_{1}^{2}, f_{22}=C_{22} V_{2}{ }^{2}, \quad f_{12}=C_{12} V_{1} V_{2}
$$

また $V_{2} ゅ\left(\bar{\gamma}^{2}\right)^{\frac{3}{2}}$ と考えて $[\eta]=\Phi\left(i^{2}\right)^{\frac{3}{2}} / M$ より $V_{2} \backsim M[\eta]$ œ $P[\eta]$ となるから，たとえば PVA の場合 $[\eta]=K P^{0.64}$ な るゆえ $V_{2} \backsim P^{1 . \theta 4}$ となる。(5)式より $\left(d E / d x_{2}\right)_{x_{2}=0}$ はほぼ $V_{2}$ に比例すると考えてよいから $\left(d E / d x_{2}\right)_{x_{2}=0}$ と $P^{1.64}$ と は比例関係にあるべきである。先に報告した2 PVA 水溶 液のデータについて検款してみると第 4 図に示すようにこ

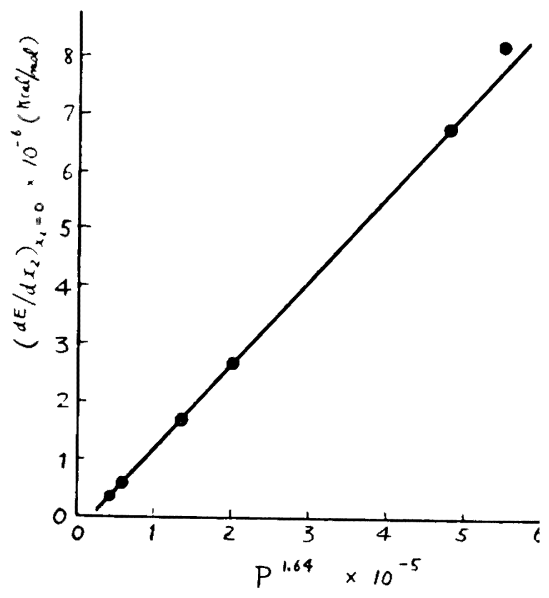

第 4 图 PVA 水溶液の $\left(d E / d x_{2}\right) x_{2}=0$ と $\mathrm{P}^{1.64}$ との関倸 の関倸が十分満足されていることがわかる。

さらにこの考え方を適用すれば前報”第(3)式より極值をとるべき組成 $x_{2}$ は

$$
x_{2}=-1 / a+\sqrt{(1 / a)^{2}-\left\{2 f_{12}-(a+2) f_{11}\right\} / a\left(f_{11}+f_{22}-2 f_{12}\right)}
$$

であり， $a=\left(V_{2} / V_{1}\right)-1$ において分子を単位と考えれば $a \gg 1$ であるから $V_{2} \fallingdotseq V_{1} a$

$$
\therefore f_{11}=C_{11} V_{1}^{2}, \quad f_{12} \fallingdotseq a C_{12} V_{1}^{2}, \quad f_{22} \fallingdotseq a^{2} C_{22} V_{1}^{2}
$$

したがってメタノール溶液の場合のように極小をとる濃度を $C(\mathrm{~g} / \mathrm{cc})$ で示せば

$$
C \operatorname{cox} x_{2} \fallingdotseq-1+\left\{1-\left(2 C_{12}-C_{11}\right) /\left(C_{22}-2 C_{12} / a\right)\right\}^{\frac{1}{2}}
$$


となって極小をとる濃度 $C$ を/cc または重量\%で示せば，ほとんど重合度に無関係となり第 2 図の実験結 果もらまく説明することができる。

また第 1 報に示したように，E〜組成関係が極大をとるためには， $2 f_{12}>f_{11}+f_{22}$ の成立することが必要で あるが, 分子を流動単位とする考え方によれば, $V_{2} \gg V_{1}$ なるゆえ $V_{2} \fallingdotseq V_{1} a$ であるから $2 f_{12}=2 C_{12} V_{1} V_{2}$ $\fallingdotseq 2 C_{12} V_{1}^{2} a, f_{11}+f_{22}=C_{11} V_{1}{ }^{2}+C_{22} V_{2}{ }^{2} \fallingdotseq C_{11} V_{1}{ }^{2}+C_{22} V_{1}{ }^{2} a^{2}$ となり $a$ が非常に大きいことを考虑すれば常に $2 f_{12}<f_{11}+f_{22}$ となって高分子溶液の場合は低分子溶液の場合のような極大をとる采は存在しないことも導き 出すことができる。

以上のように流動単位を分子自身と考えて，低分子の式を拡張すれば実験事実をきわめてうまく説明する ことができる。ただ低分子の場合においてさえ，会合液体などに対しては十分成立しなかった式を高分子溶 液の場合にそのまま適用することは，いささか乱暴であるし，V 2 をそのまま高分子 1 個の体積と考える考え 方にも疑問があるのでここでは実験事実を十分説明できるというにとどめたい。

なお分岐の効果については測定範囲程度の分岐では，その影制は重合度の中人含まれてしまって，現われ てこないようである。したがって普通のPVAc では流動の活性化ェネルギーには分岐の影響はないと考え て,さしつかえないと思われる。

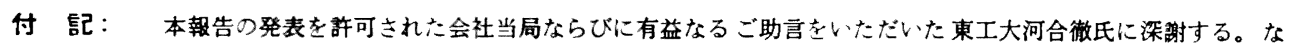
おこの報告:滈分子学会第 6 回年次大会 $(1957,6.1$ 東京)にて発表した。

\section{文献}

1) 内藤：高化, 投稿中

2) 内藤, 浮田, 小南: 高化 14, 117 (1957)

\section{Studies on the Solution of Polyvinyl Acetate}

\section{Effect of Molecular Weight and Branching on the Apparent Activation Energy of Flow of Polyvinyl Acetate Solution}

\section{By Ryunosuke Naito}

The effect of the molecular weight and branching of polyvinyl acetate was studied on the apparent activation energy, $E_{r}$, of flow of its solution. (1) $E_{r}$ increases linearly with the molecular weight when good solvent such as aceton or benzene is used. (2) In the case of methanol, the plot of $E_{r}$ vs. concentration has minimum and the absolute value of the slope of this curve increases with the molecular weight. (3) The concentration at which this curve has minimum is nearly constant, about 2 weight $\%$, independently of the molecular weight. 